\title{
Dealing with Discontinuity in Cancer Care Trajectories: Patients' Solutions
}

\author{
Debbie Vermond ${ }^{1}$ (1) Souad el Habhoubi ${ }^{1}$ Esther de Groot $^{1} \cdot$ Larike Bronkhorst $^{2} \cdot$ Niek de Wit $^{1} \cdot$ Dorien Zwart $^{1}$
}

Accepted: 8 June 2021 / Published online: 25 June 2021

(c) The Author(s) 2021

\begin{abstract}
Introduction Patients with cancer require specialized care from different care providers, challenging continuity of care in terms of information, relationships, and/or management. The recognition of discontinuity of care has led to different initiatives by the healthcare system over the years. Yet, making use of the theory on boundary objects and brokers, this research explores the active role of patients themselves in resolving discontinuity along their care trajectories.

Methods Semi-structured interviews were conducted with 33 patients to unravel the discontinuities that they experience and their attempts to resolve these. Interview data were analyzed using directed-content analysis informed by concepts from boundary crossing literature (i.e., data were searched for potential boundary objects and brokers).

Results To re-establish continuity of care, patients actively use the objects and people provided by the healthcare system when these meet their needs. Patients also introduce own objects and people into the care trajectory. As such, information and management discontinuity can typically be resolved. Relational continuity appears to be more difficult to resolve, in some cases leaving patients to take drastic measures, such as changing care providers.

Discussion The use of boundary crossing theory in improving care from a patient perspective is relatively novel. When patients and providers together address the objects and people that support establishing continuity of care, a continuous care process may be encouraged. We advocate an integrated approach, rather than provider or healthcare system initiatives exclusively, to patient care and continuity.
\end{abstract}

\section{Introduction}

"When you start talking about a radiologist and an internist, an oncologist and an assistant here, and an intern, resident-well, how should I know?" (patient being treated for cervical cancer).

Patients requiring substantive specialized care are often treated by different care providers. Because of complex needs, they receive consultation and treatment from multiple healthcare specialties. Yet, as a result of specialization, patients experience a lack of coordination that integrates the

Debbie Vermond and Souad el Habhoubi were shared first authorship.

Debbie Vermond

D.Vermond@umcutrecht.nl

1 Julius Center for Health Sciences and Primary Care, University Medical Center Utrecht, Utrecht University, P.O. Box 85500, 3508 GA Utrecht, The Netherlands

2 Faculty of Social and Behavioural Sciences, Department of Education, Utrecht University, Utrecht, The Netherlands care provided by different care providers [1,2]. Continuity of care is threatened as a consequence [3-5]. Patients are required to navigate between different care providers, but experience boundaries between them. These boundaries are typically considered as relatively impermeable barriers to communication and coordination, and undeniably lead to discontinuity of care with occasionally severe consequences (e.g., psychological distress or medical errors with higher rates of hospitalization) [6-12]. Meanwhile, research has convincingly shown that boundaries are not insurmountable and offer opportunities for change [13-18]. Accordingly, by understanding the discontinuities that patients experience, and considering these as opportunities to reestablish continuity, healthcare systems may optimize their approaches towards increasingly specialized patient care [19].

Patients' experiences of continuity and discontinuity can be understood along three dimensions: informational, relational and management [7]. Discontinuity along the informational dimension refers to a lack of relevant patient information amongst different care providers (e.g., on prior events), but also includes deficits in the care provider's knowledge about the patient's preferences, values, and context. The 


\section{Key Points for Decision Makers}

Patients are very active in (re-)establishing continuity of care across their own care trajectories, but relational continuity in particular requires special attention and efforts from both patients and providers.

The boundary crossing theory, addressing how people bridge and connect different settings, may support patients and providers to establish continuity of care in the current context of increasingly fragmented healthcare systems where patients are seen by multiple doctors in different settings.

An integrated approach towards continuity of care that takes full advantage of both providers' and patients' roles may provide new opportunities for healthcare to enhance the patient experience.

importance of (ongoing) relationships between patients and providers is captured in the relational dimension: relational discontinuity refers to the absence of such relationships. Furthermore, discontinuity along the management dimension refers to circumstances in which patients receive care from different providers that is not connected in a coherent way $[5,10]$. Continuity and discontinuity of care should not be viewed as rigid opposites, but as two ends of a spectrum: care experiences may tend, to a greater or lesser extent, towards one end [20]. The recognition of discontinuity of care has led to different initiatives in the healthcare system over the years (e.g., facilitating communication via the electronic medical record, improving patient education, and/ or introducing discharge planning), but the active role that patients themselves play is typically overlooked.

Accordingly, in contrast to much research on continuity and discontinuity of care, which has largely focused on how discontinuity is resolved (and continuity established) from a provider or organizational perspective, this research invites patients to consider what discontinuities they experience, and how they (attempt to) resolve them. The theory on boundary crossing is particularly helpful to improve understanding of the relatively unknown role of the patient in resolving discontinuity at boundaries [17, 21, 22]. Within the field of integrated care, as in other fields concerned with collaboration across boundaries, this theory has received growing interest [23, 24]. It offers potential approaches to cross boundaries; the most notable approaches are boundary objects and brokers. Boundary objects and brokers are objects and people, respectively, that bring different social worlds or working practices together or bridge the gap between them [25-28]. Boundary objects are typically portrayed as "both inhabiting several intersecting worlds and satisfying the informational requirements of each of them"-hence, they are a "means of translation" [22, 29]. According to Star, boundary objects can be interpreted flexibly, are tailored to local information and work needs, and are dynamic in use within and across practices [17, 29]. Brokers-sometimes referred to as boundary subjectshave been depicted as "interlocutors": translating, coordinating, and aligning different perspectives or meanings across practices [30-33]. As boundary objects and brokers arise from both information and work needs, we posit that they may resolve discontinuity in care trajectories along all three dimensions depicted above [29].

Examples of objects and people introduced by the healthcare system to bridge boundaries (i.e., intended boundary objects and brokers) are numerous (e.g., the electronic medical record or a care coordinator), but the necessity and productivity of these objects and people-as experienced by patients-remain a largely unexplored area. As the bridging capacity of boundary objects and brokers is not an inherent property of the object or the person, but rather comes to life in active work and sense-making, we aim to explore whether the objects and people that are introduced by the healthcare system (i.e., intended boundary objects and brokers) are productive to patients [22, 25, 34]. Secondly, we aim to explore whether patients introduce objects and people themselves to (re)establish continuity of care. In doing so, the active contribution of patients, as potential levers for effective change, might be more successfully utilized [19].

\section{Methods}

\subsection{Study Design and Sample}

This study is part of a larger action research project on collaborative care, called ZOUT (a Dutch acronym for "The right care at the right place in Utrecht"). The aim of that project is to explore the current interprofessional collaboration within a regional healthcare system (Utrecht, The Netherlands), but especially to delve into possibilities for improvement.

In this exploratory study, interviews with patients diagnosed with cancer were conducted to unravel the discontinuities that patients experience and their attempts to resolve these. Patients diagnosed with cancer were selected because 
of the inherent complexity and fragmentation of cancer care, for which achieving continuity of care across the cancer care pathway is particularly complex. Patients were invited to participate by email based on their indication in another, related study that they could be approached for comparable research into cancer care. Of the 127 invited patients, 88 patients did not respond and six did not want to participate. The remaining 33 patients received an information sheet about the study, including study procedures, and were then approached to schedule an appointment for the interview.

\subsection{Data Collection and Analysis}

Using video or audio calls, two researchers with backgrounds in biomedical and educational science (DV and $\mathrm{SeH})$ conducted semi-structured interviews with 33 patients diagnosed with cancer. The interview questions were pilot tested in an interview with both researchers present. At the start of the interviews, consent was obtained (in addition to the written consent in the other, related study that they participated in) to record the interview. Patients could ask questions about the information they had received in advance. On average, an interview lasted 55 min (range 23-95 min) and followed the interview guide that focused on mapping the patient's trajectory and the collaboration between different healthcare providers in particular (see the electronic supplementary material). In light of the theoretical nature of the boundary crossing concepts, patients were not asked to identify (dis)continuity, (intended) boundary objects or brokers themselves, rather these were identified in the patients' stories by the researchers.

The interviews were transcribed ad verbatim, anonymized, and uploaded to the qualitative data analysis software NVivo 12 for analysis. We used the directed-content analysis method informed by conceptually theoretical concepts stemming from the literature on boundary crossing [35]. These concepts guided the initial development of the codebook, and were complemented by inductive coding. Each transcript was coded independently by two researchers (DV, SeH), with discrepancies reconciled through negotiated consensus. A third and fourth researcher (EdG, LB) were consulted when consensus could not be reached.

Coding matrices and crosstabs were used to explore the experience of (dis)continuity across patients, and to find out if and how patients responded to that. For each patient, several expressions of the same (dis)continuity experience were counted as one. Data saturation was considered to have been reached, although saturation is a contested concept in the qualitative research domain [36]. Given the fact that the interpretation of data was primarily guided by the researchers' theoretical and methodological expertise on (dis)continuity and boundary crossing, participants were not asked to provide feedback on the data [36]. The standards for reporting qualitative research (Consolidated Criteria for Reporting Qualitative Research [COREQ]) were applied [37].

\section{Results}

At one or several points across their care trajectories, all 33 patients experienced continuity of care, and 30 out of 33 patients also experienced discontinuity of care (Table 1). Of the three dimensions of discontinuity, discontinuity along the relational dimension was experienced most often, across all age categories and types of cancer and independently of gender. Relational discontinuity referred to either a lack of trust or a sense of being known or seen, as well as the lack of sustainable, ongoing relationships:

Well, I'd have liked to wait a day longer to discuss the results rather than talk to another doctor about it, and to have a choice about that. So I'd have liked them to say 'You can come on Monday and talk to another doctor than the one who operated on you or you can come on Tuesday and talk to your own surgeon.' (Patient 20)

This excerpt signals how discontinuity in one domain can be associated with pursuing continuity in another. Providing test results quickly (important for information continuity) in this case resulted in discontinuity in the relational domain (receiving these results from another care provider). Experiences of information discontinuity were mostly the result of conflicting information: "It's the surgeon telling me 'I'd have your lymph nodes removed' even though the dermatologist had said "Are you sure you really want to have that done?" (patient 5).

The majority of the patients, except for those who suffered from skin cancer, also experienced a form of discontinuity in the management of their care. Particularly often, patients missed a coherent referral management strategy addressing their psychosocial problems associated with their illness experiences: "Well, in the hospital you're in the hospital and you have an operation and what I really miss is the psychological part [...] Because in my experience, you have to check out everything for yourself, you have to ask everywhere. Just give us some guidance" (patient 33).

Table 1 shows that, regardless of the extent to which patients experience discontinuity, the vast majority of them uses (initiated by the system) or introduces (introduced by themselves) objects and people to (re-)establish continuity of care.

Examples of objects and people that patients used or introduced across their care trajectories are listed in Table 2 and discussed below. 
Table 1 Number of discontinuities and use of objects and people for each patient
Table 2 Examples of objects and people patients used to re-establish continuity of care

\begin{tabular}{|c|c|c|c|c|c|c|c|c|c|c|c|}
\hline & \multirow[t]{2}{*}{ Age } & \multirow[t]{2}{*}{ Gender } & \multirow[t]{2}{*}{ Type of cancer } & \multicolumn{4}{|c|}{ Discontinuities } & \multicolumn{2}{|l|}{ Objects } & \multicolumn{2}{|l|}{ People } \\
\hline & & & & $\mathrm{T}$ & I & M & $\mathrm{R}$ & Initiated & Introduced & Initiated & Introduced \\
\hline 1 & $50-70$ & Female & Intestinal & 0 & 0 & 0 & 0 & $\checkmark$ & $\checkmark$ & $\checkmark$ & $\checkmark$ \\
\hline 2 & $70-80$ & Male & Prostate & 0 & 0 & 0 & 0 & - & - & $\checkmark$ & $\checkmark$ \\
\hline 3 & $50-70$ & Male & Skin & 0 & 0 & 0 & 0 & $\checkmark$ & $\checkmark$ & $\checkmark$ & $\checkmark$ \\
\hline 4 & $50-70$ & Male & Multiple & 1 & 0 & 1 & 0 & $\checkmark$ & - & $\checkmark$ & - \\
\hline 5 & $70-80$ & Male & Skin & 1 & 1 & 0 & 0 & $\checkmark$ & - & $\checkmark$ & $\checkmark$ \\
\hline 6 & $50-70$ & Male & Skin & 1 & 0 & 0 & 1 & $\checkmark$ & $\checkmark$ & - & $\checkmark$ \\
\hline 7 & $70-80$ & Female & Skin & 1 & 0 & 0 & 1 & - & - & - & - \\
\hline 8 & $50-70$ & Female & Breast & 2 & 0 & 0 & 2 & $\checkmark$ & - & $\checkmark$ & $\checkmark$ \\
\hline 9 & $50-70$ & Male & Intestinal & 2 & 0 & 1 & 1 & $\checkmark$ & - & $\checkmark$ & $\checkmark$ \\
\hline 10 & $80+$ & Male & Skin & 2 & 1 & 0 & 1 & $\checkmark$ & - & $\checkmark$ & $\checkmark$ \\
\hline 11 & $50-70$ & Female & Breast & 3 & 3 & 0 & 0 & $\checkmark$ & $\checkmark$ & $\checkmark$ & $\checkmark$ \\
\hline 12 & $<50$ & Female & Breast & 3 & 0 & 2 & 1 & $\checkmark$ & $\checkmark$ & $\checkmark$ & - \\
\hline 13 & $<50$ & Female & Skin & 3 & 2 & 0 & 1 & - & $\checkmark$ & $\checkmark$ & $\checkmark$ \\
\hline 14 & $50-70$ & Female & Breast & 4 & 2 & 0 & 2 & $\checkmark$ & $\checkmark$ & $\checkmark$ & $\checkmark$ \\
\hline 15 & $70-80$ & Female & Breast & 4 & 0 & 2 & 3 & - & - & - & $\checkmark$ \\
\hline 16 & $70-80$ & Female & Intestinal & 4 & 0 & 1 & 3 & $\checkmark$ & - & $\checkmark$ & $\checkmark$ \\
\hline 17 & $50-70$ & Female & Lung & 5 & 0 & 0 & 5 & $\checkmark$ & - & $\checkmark$ & $\checkmark$ \\
\hline 18 & $50-70$ & Male & Multiple & 5 & 3 & 3 & 2 & - & - & $\checkmark$ & $\checkmark$ \\
\hline 19 & $50-70$ & Female & Breast & 6 & 4 & 5 & 0 & $\checkmark$ & $\checkmark$ & $\checkmark$ & $\checkmark$ \\
\hline 20 & $50-70$ & Female & Breast & 7 & 5 & 1 & 4 & $\checkmark$ & - & $\checkmark$ & $\checkmark$ \\
\hline 21 & $50-70$ & Female & Breast & 7 & 2 & 2 & 4 & $\checkmark$ & - & $\checkmark$ & - \\
\hline 22 & $80+$ & Female & Multiple & 7 & 1 & 5 & 2 & $\checkmark$ & $\checkmark$ & $\checkmark$ & $\checkmark$ \\
\hline 23 & $50-70$ & Female & Multiple & 7 & 1 & 6 & 1 & $\checkmark$ & - & $\checkmark$ & $\checkmark$ \\
\hline 24 & $50-70$ & Female & Multiple & 7 & 3 & 3 & 3 & $\checkmark$ & $\checkmark$ & $\checkmark$ & $\checkmark$ \\
\hline 25 & $<50$ & Female & Breast & 8 & 1 & 3 & 5 & $\checkmark$ & $\checkmark$ & $\checkmark$ & $\checkmark$ \\
\hline 26 & $50-70$ & Female & Breast & 9 & 4 & 5 & 5 & - & $\checkmark$ & $\checkmark$ & - \\
\hline 27 & $70-80$ & Male & Intestinal & 9 & 6 & 6 & 5 & $\checkmark$ & - & - & $\checkmark$ \\
\hline 28 & $80+$ & Female & Breast & 10 & 6 & 5 & 2 & $\checkmark$ & $\checkmark$ & $\checkmark$ & $\checkmark$ \\
\hline 29 & $50-70$ & Male & Intestinal & 10 & 8 & 6 & 3 & $\checkmark$ & $\checkmark$ & $\checkmark$ & $\checkmark$ \\
\hline 30 & $70-80$ & Male & Multiple & 11 & 2 & 7 & 5 & $\checkmark$ & - & $\checkmark$ & $\checkmark$ \\
\hline 31 & $70-80$ & Female & Breast & 12 & 3 & 6 & 4 & $\checkmark$ & $\checkmark$ & $\checkmark$ & $\checkmark$ \\
\hline 32 & $<50$ & Female & Cervical & 12 & 4 & 3 & 6 & $\checkmark$ & $\checkmark$ & $\checkmark$ & $\checkmark$ \\
\hline 33 & $50-70$ & Female & Multiple & 24 & 14 & 10 & 6 & $\checkmark$ & $\checkmark$ & $\checkmark$ & $\checkmark$ \\
\hline
\end{tabular}

Separate numbers may exceed the total number of (dis)continuities due to overlap along the distinct dimensions of (dis)continuity

$T$ total, $I$ informational, $M$ management, $R$ relational, Initiated initiated by the system, introduced introduced by patients themselves

\begin{tabular}{lllll}
\hline Objects & & & People & \\
\cline { 5 - 5 } Initiated & Introduced & & Initiated & Introduced \\
\hline Electronic medical record & Notebook/diary & & General practitioner & Self \\
Information leaflet & Recorder & & Case manager & Partner \\
Appointment card & Internet forum & & Nurse & Friend \\
\hline
\end{tabular}

Initiated initiated by the system, introduced introduced by patients themselves 


\subsection{Objects Initiated by the System to Establish Continuity}

Numerous objects are initiated by the system and identified by patients: 27 out of 33 patients ( $82 \%$ ) recognized that the system initiated an object to establish continuity of care (i.e., intended boundary objects). These objects ranged from the electronic medical record to patient information leaflets. The use of objects occurs across all ages, sexes, and among all types of cancer.

However, not all of these objects were deemed necessary by patients, or perceived as enhancing the patient experience: "No, I didn't feel the need for them [information leaflets]" (patient 1). Also, the effectivity of the objects was questioned. A patient explained that she wanted to consult her medical record to establish (information) continuity, but that accessing her medical record in fact only had the opposite effect and caused confusion: "Well that really, uhm, uhm, freaked me out. And I read it on Friday afternoon, just before the weekend. So there's no one available then" (patient 20).

In line, other patients recognized the difficulty of comprehending medical information themselves: "Well, then you just think: what is this actually saying? Because I don't know what it means" (patient 33). They avoid using the object for that reason and advise care providers accordingly for using the medical record: "If I could offer one piece of advice to uhm... uhm... doctors, it would definitely be to remember that people read their own medical records too" (patient 20).

\subsection{Objects Introduced by Patients to Establish Continuity}

Patients also actively introduce objects themselves to establish continuity of care. It became clear from about half of the patient stories $(17 / 33)$ that they introduced one or several objects throughout their trajectories. The objects that patients introduced range from the use of notebooks to prepare and answer questions to organizing all information in one folder:

So I had a notepad at home and I'd think, oh yeah, I have to ask about this and that. Because when you're sitting there, you can't think of any questions. So I actually write things down, when I have an important appointment I always write everything down. (Patient 14)

Yes. I made a file for the breast operation... because it's all pretty confusing and you can look up a lot of things on the internet... so I thought, well I'll just make a separate folder [...] I even have the operative report in there. I asked for it afterwards [...]. And that's, that's, that's extra information you don't get when you come in for a check-up. (Patient 28)

\subsection{Relying on Objects for Information, Management, and Relational Continuity}

Although the number of experiences of discontinuity along the informational dimension across all patients was the lowest, it most often elicited the use of objects. For example, the use of the internet: "No, no, not really. Because I remember I googled it and then I was like uh oh, it's this, shit, this is it" (patient 13). Object use for establishing continuity along the management dimension was often related to bringing clarity in turbulent times ("it is a rollercoaster"), for example, using an agenda within the electronic medical record.

Relational continuity was the only dimension of continuity for which objects appeared of little help. In exceptional cases, patients resolved discontinuity along the relational domain using objects, avoiding face-to-face interactions in doing so:

No, that's uhm... we had to fill in a questionnaire [at the hospital] about our dealings with our general practitioner, I think. And my husband wrote that down [poor communication with general practitioner]... And I think she read it and then she started showing more of an interest. (Patient 16)

Yet, patients occasionally chose to leave the relational discontinuity unresolved and sought healthcare somewhere else instead:

So, uhm, well, then you just wait a few weeks for her and you think: okay, nothing's going to come of this. Hahaha. And then I lost all motivation to have another check-up in July. I got a call to go for a check-up [from hospital A] and I said: 'I' $m$ out of the country and uhm I'll make an appointment another time.' Anyway, I did do that later at hospital B. (Patient 26)

\subsection{People Initiated by the System to Establish Continuity}

In addition to the use of objects by the majority of patients, most patients (29/33) also referred to at least one person introduced by the healthcare system to help them throughout their care trajectory (i.e., intended brokers). These people included the nurse practitioner (especially in the case of breast cancer) and the general practitioner.

However, comparable to what patients experienced regarding objects provided by the system, not all people that the system offers to help enhanced the patient experience. Disagreement on the necessity and effectivity of the general practitioner to translate and coordinate care was the highest. 
Some patients expected the general practitioner to have this translating and coordinating role and were disappointed if he or she did not fulfill this role. Others recognized this role of the general practitioner but had no need for that or considered it ineffective:

Patients have a lot of questions a lot of the time and they ask them at the most impossible moments and they need somewhere to go to get answers. And their general practitioner doesn't know enough of the whole picture to be able to make a decision. It has to be someone who has a close relationship with the specialist. (Patient 27)

Similarly, the role of the nurse practitioner was appreciated differently by different patients. However, most of the patients considered the nurse practitioner important for continuity of care within the hospital:

No, no. No, I just think that they really shouldn't underestimate the role of the nurse practitioner... And there should also really uhm....uhm.... be time for that, say... because you see an oncologist, a surgeon, a, a, a, uhm.... plastic surgeon, a radiologist. You see them all and you build up relationships with them, but they aren't constant factors and she's the only constant factor. (Patient 24)

\subsection{People Introduced by Patients to Establish Continuity}

Throughout their care trajectories, 28 out of 33 patients also actively introduced people to establish continuity themselves: family and friends were often taken to consultations or asked for help otherwise. In other situations, patients translated between different perspectives themselves.

Patients translated and coordinated between different healthcare providers or organizations, either because they seized that role or because they had the feeling that the design of the healthcare system required them to do so: "Of course I made sure by asking the surgeon and the dermatologist whether their findings would be passed on to my general practitioner too" (patient 10). To some extent, either or not using objects, patients may also act as an interlocutor between their own experiences. A notebook, for example, may act as a means to manage knowledge from diverse practices within a person over time. In addition, they bridged between the healthcare system and their family and friends:

So my sisters saw it, my husband, my mother. I said, if you want, you can come with me to where the screens are and you can see where I am now and what they're doing to me. That way you'll see that it's not scary. It's intense, but it's not scary [...] So, well, they said that it did help them understand what I'm going through. (Patient 32)

Moreover, occasionally people and objects were employed simultaneously: "I printed out two questionnaires, one for myself... And the other one for my friend, or whoever was going with me, so that we could copy down the answers on it" (patient 14).

\subsection{Relying on People for Information, Management, and Relational Continuity}

Patient experiences with regard to employing people to (re-) establish continuity of care were mostly related to experiences of discontinuity along the informational and management dimension. Again, discontinuity along the relational dimension remained mostly unresolved. Following management discontinuity (e.g., long waiting times), support was often found amongst family members or friends. When patients faced information discontinuity, they often felt the need to align perspectives themselves:

And, if I remember correctly-it was almost five years ago now-I noticed a subtle difference between the dermatologist and the surgeon [...] No, that just makes it easier. It did make me feel like: This is real life. This is a real choice, it's really up to me. (Patient 5)

When patients experienced relational discontinuity, intended brokers by the system were of less help. In line with the earlier excerpt on how the efforts from care providers to minimize (information) discontinuity only increased (relational) discontinuity, people introduced by the system may also have the opposite effect of what was intended. In fact, when the introduction of an intended broker raises expectations of relational continuity in patients, and these expectations are not met, things only got worse:

And when I send an e-mail uhm to the attending nurse in hospital B and I get a reply four days later saying 'Go see your general practitioner,' then I'm like: thanks, but no thanks. So I broke off all contact with her. I was like, I really don't want to have anything to do with her anymore. I also told my specialist, don't ever mention her name to me again. It made absolutely no sense, I said. It would defeat the purpose. (Patient 27)

\section{Discussion}

In considering new interprofessional approaches towards increasingly specialized patient care, the healthcare system might benefit from understanding the discontinuities that patients experience, and if and how they re-establish 
continuity. This study explored patients' experiences with regard to discontinuity along the informational, relational, and management dimensions, as well as their actions to deal with it. Based on our analysis from a boundary crossing perspective, this study demonstrates that patients are very active in resolving discontinuity (or establishing continuity) across their own care trajectories. They often employ the objects and people that are provided to them by the health care system (i.e., intended boundary objects and brokers), especially in the case of information and management discontinuity, but also introduce objects and people to establish continuity in their care trajectory themselves.

Yet, the productivity of objects and people in establishing continuity of care, and accordingly their classification as boundary objects and brokers, should not be taken for granted. The current study showed how information leaflets, for example, introduced by the healthcare system as an (intended) boundary object, do not always have a bridging function. Similarly, a general practitioner may be a broker, but may also be experienced as "just one of the care providers involved." Moreover, theoretically the objects introduced by patients in this study (e.g., the notebook or the self-created folder with collected information) to establish continuity may not (yet) be considered boundary objects in the traditional sense of the concept. Currently, these objects appear to be used only by the patients themselves, and can thus not be said to "inhabit intersecting worlds," even though patients did report how these objects satisfied their own informational requirements in their trajectories of care across different practices [22]. Accordingly, we argue that, rather than debating the definitions of boundary objects and brokers, it is particularly the underlying rationale of boundary objects and brokers-bridging different worlds-that may help in understanding and advancing continuity of care. As such, the added value of using concepts as boundary objects and brokers to advance continuity of care does not lie in prescribing the use of certain objects and people, but in understanding why and how objects and people support and sustain continuity of care differently for different patients.

The extent to which objects and people bridged different worlds in the current study varied for the three dimensions of discontinuity. Patients often relied on objects and people to resolve discontinuity along the informational dimension, and to a lesser extent in response to discontinuity along the management dimension. Although discontinuity along the relational dimension was experienced most often, it remained largely unresolved-patients rather changed care providers to avoid it. In the light of previous research pointing to relational continuity as the dimension of continuity that patients value the most, this is particularly relevant [7, $38,39]$. The core of the difference may be in the nature of the discontinuity: the nature of the patient-provider relationship prevents the use of a "cookbook" approach and requires a more contextual, individualized understanding of individual needs and preferences $[40,41]$. Relational continuity is a "two-way street" where the face-to-face interaction between patient and provider is key. In contrast, information and management continuity benefit from general initiatives at the system level, e.g., by initiating intended boundary objects (e.g., automated exchange via the electronic medical record) or intended brokers (e.g., the general practitioner) to establish continuity across a patient's trajectory.

Relational continuity may rather benefit from initiatives on a more personal level, specifically bridging differences between care providers and patients, i.e., "humanization of care." Humanization of care adopts a more holistic perspective to the process of care and interactions compared to other, well known concepts such as patient-centered or person-centered care [42]. It explicitly focuses on all the stakeholders involved in the care process (i.e., patient as well as provider) and accordingly may best address the relational aspect of care. Patient-provider relationships mostly benefit from a basis of trust and a sense of being known or seen [43-45]. Especially when patients expect such properties in relationships with their providers (in their relationships with intended brokers in particular), relational discontinuity is a hidden risk. Moreover, our findings indicate that patients may face difficulties raising relational discontinuity with their providers. Accordingly, the role of providers may be to actively seek patient feedback, put the subject of relational continuity explicitly on the agenda with patients and develop more positive and sustainable relationships with their patients [46, 47].

While the theory on boundary crossing is more often used in considerations to improve interprofessional care, its use in understanding care from a patient perspective is relatively novel $[48,49]$. The importance of involving the patient perspective has been widely recognized over the last decade, but research is often limited to rather "passive" patient participation [50-52]. Again, the question is often about how patients can be empowered to play an active role in their care process, as if patients are not yet seen as active players $[38,53,54]$. By approaching the care process the other way around, starting from the role of the patient, this study responds to previous calls to shift from the traditional view of the patient as a "passive recipient of care" to the new view of patients as "integral to the improvement of the innovation process" [55-58].

This study revealed that patients already make a substantial contribution to establishing continuity of care. In contrast to previous studies, we found that patients are, to different degrees, active in managing their care [7]. Their 
active role has turned out to be most evident in situations of discontinuity along the informational and management dimension. Our results suggest that patients employ (boundary) objects especially to resolve information and management discontinuity, and that they take on a coordinating role, or even broker, mostly when they experience discontinuity along the informational dimension. Accordingly, instead of continuing to explore what patients might be able to add, we advocate (1) gaining more insight into what patients already contribute, and (2) providers to start routinely asking their patients about, and acting upon, the objects and people they rely on to do that while explicitly addressing expectations on relational continuity. It is time to put a hitherto mainly theoretical concept in practice: addressing (intended) boundary objects and brokers in daily care may provide opportunities to respond to those and to take healthcare to the next level.

The main strength of this study is the examination of patient experiences from a boundary crossing perspective, highlighting patients' active roles in establishing continuity of care by using and introducing objects and people (intended boundary objects and brokers). A limitation may be that these objects and people were identified in the patients' stories by the researchers rather than by the patients themselves, and may thus be underestimated. Furthermore, the majority of the patients included in this study had practically completed their care trajectories. Emotions and feelings regarding their experiences of discontinuity may thus have been weakened or forgotten. However, since we primarily focused on their actions upon experiences of discontinuity-and not on the experiences themselves-we do not expect this to have had a significant impact on our results. Rather it may have helped because patients could now view their care process from a distance.

Advocates for patient involvement argue that seeking the active contribution of patients and families in the coordination of care can help mitigate the complexity of the specialized healthcare system, and lead to improvements in care continuity. This study extends and develops the line of argument for patient participation by exploring the role that patients already have in crossing the boundaries between multiple care providers. We do not argue for initiatives from the healthcare system exclusively to resolve this in the future, but for an integrated approach in which the contributions of all are acknowledged to collectively improve care. Improved understanding of how patients employ objects and people to address discontinuity, and where they need help, may support the healthcare system to negotiate its way through the multitude of dependencies and influences that complicate the increasingly specialized, collaborative patient care.

Supplementary Information The online version contains supplementary material available at https://doi.org/10.1007/s40271-021-00535-x.

\section{Declarations}

Funding This work was supported by a grant from ZonMw (project number 516006002). ZonMw aims to promote quality and innovation of health research to make healthcare better and to keep it affordable. ZonMw had no role in study design, in the collection, analysis, and interpretation of data, in the writing of the manuscript, or in the decision to submit the manuscript for publication.

Conflict of interest The authors report no declarations of interest.

Ethics approval This manuscript was prepared in compliance with ethical standards. The study was not subject to the Dutch Medical Research Involving Human Subjects Act (WMO), so the Medical Ethics Review Committee (METC) waived the necessity for formal approval.

Consent to participate Informed consent was obtained from all individual participants included in the study.

Consent for publication Before consenting, participants were informed that their data would be analyzed for a research purpose and accordingly may be published in a journal article.

Availability of data and material The data sets generated and analyzed during the study are unavailable.

Code availability The codebook is available upon request.

Authors' contributions All authors have made a substantial, direct contribution to this study. The study was designed by DV, SeH, DZ, EdG, and LB. Data collection and analysis was conducted by DV and $\mathrm{SeH}$ under the supervision of EdG and LB. DV, EdG, and LB wrote the manuscript. All authors critically revised the manuscript for intellectual content and approved the final version.

Open Access This article is licensed under a Creative Commons Attribution-NonCommercial 4.0 International License, which permits any non-commercial use, sharing, adaptation, distribution and reproduction in any medium or format, as long as you give appropriate credit to the original author(s) and the source, provide a link to the Creative Commons licence, and indicate if changes were made. The images or other third party material in this article are included in the article's Creative Commons licence, unless indicated otherwise in a credit line to the material. If material is not included in the article's Creative Commons licence and your intended use is not permitted by statutory regulation or exceeds the permitted use, you will need to obtain permission directly from the copyright holder. To view a copy of this licence, visit http://creativecommons.org/licenses/by-nc/4.0/.

\section{References}

1. Van Achterberg T, Stevens FCJ, Crebolder HFJM, De Witte LP, Philipsen H. Coordination of care: effects on the continuity and quality of care. Int J Nurs Stud. 1996;33(6):638-50. https://doi. org/10.1016/S0020-7489(96)00021-1.

2. Stange KC. The problem of fragmentation and the need for integrative solutions. Ann Fam Med. 2009;7(2):100. https://doi.org/ 10.1370/afm.971.

3. Waibel S, Henao D, Aller MB, Vargas I, Vazquez ML. What do we know about patients' perceptions of continuity of care? A meta-synthesis of qualitative studies. Int J Qual Health Care. 2012;24(1):39-48. https://doi.org/10.1093/intqhc/mzr068. 
4. Guthrie B, Saultz JW, Freeman GK, Haggerty JL. Continuity of care matters. BMJ. 2008;337: a867. https://doi.org/10.1136/bmj. a867.

5. Reid R, Haggerty J, McKendry R. Defusing the confusion: concepts and measures of continuity of health care. Vancouver, B.C.: Centre for Health Services and Policy Research, University of British Columbia; 2002.

6. Philipsen H, Stevens FCJ. Modernization, rationality and continuity of care: theoretical concepts and empirical findings. Sociol Focus. 1997;30(2):189-204. https://doi.org/10.1080/00380237. 1997.10570691.

7. Jackson J, MacKean G, Cooke T, Lahtinen M. Patient and provider experiences with relationship, information, and management continuity. Patient Exp J. 2017;4(3):10. https://doi.org/10.35680/ 2372-0247.1192.

8. van Servellen G, Fongwa M, Mockus DE. Continuity of care and quality care outcomes for people experiencing chronic conditions: a literature review. Nurs Health Sci. 2006;8(3):185-95. https://doi. org/10.1111/j.1442-2018.2006.00278.x.

9. van Walraven C, Oake N, Jennings A, Forster AJ. The association between continuity of care and outcomes: a systematic and critical review. J Eval Clin Pract. 2010;16(5):947-56. https://doi.org/10. 1111/j.1365-2753.2009.01235.x.

10. Haggerty JL, Roberge D, Freeman GK, Beaulieu C. Experienced continuity of care when patients see multiple clinicians: a qualitative metasummary. Ann Fam Med. 2013;11(3):262-71. https:// doi.org/10.1370/afm.1499.

11. Moore C, Wisnivesky J, Williams S, McGinn T. Medical errors related to discontinuity of care from an inpatient to an outpatient setting. J Gen Intern Med. 2003;18(8):646-51. https://doi.org/10. 1046/j.1525-1497.2003.20722.x.

12. Kislov R. Selective permeability of boundaries in a knowledge brokering team. Public Admin. 2018;96(4):817-36. https://doi. org/10.1111/padm.12541.

13. Greig G, Entwistle VA, Beech N. Addressing complex healthcare problems in diverse settings: insights from activity theory. Soc Sci Med. 2012;74(3):305-12. https://doi.org/10.1016/j.socscimed. 2011.02.006.

14. Engestrom Y, Sannino A. Studies of expansive learning: foundations, findings and future challenges. Educ Res Rev. 2010;5(1):124. https://doi.org/10.1016/j.edurev.2009.12.002.

15. O'Leary N, Boland P. Organization and system theories in interprofessional research: a scoping review. J Interprof Care. 2020;34(1):11-9. https://doi.org/10.1080/13561820.2019.16328 15.

16. Engeström Y. Expansive learning at work: toward an activity theoretical reconceptualization. J Educ Work. 2001;14:133-56. https:// doi.org/10.1080/13639080020028747.

17. Akkerman SF, Bakker A. Boundary crossing and boundary objects. Rev Educ Res. 2011;81(2):132-69. https://doi.org/10. 3102/0034654311404435.

18. Akkerman S, Bakker A. Learning at the boundary: an introduction. Int J Educ Res. 2011;50:1-5. https://doi.org/10.1016/j.ijer. 2011.04.002.

19. O'Keefe M, Ward H. Implementing interprofessional learning curriculum: how problems might also be answers. BMC Med Educ. 2018;18(1):132. https://doi.org/10.1186/s12909-018-1231-1.

20. Walters AH, Oyebode JR, Riley GA. The dynamics of continuity and discontinuity for women caring for a spouse with dementia. Dementia. 2010;9(2):169-89. https://doi.org/10.1177/1471301209 354027.

21. Engeström Y, Engeström R, Kärkkäinen M. Polycontextuality and boundary crossing in expert cognition: learning and problem solving in complex work activities. Learn Instr. 1995;5(4):319-36. https://doi.org/10.1016/0959-4752(95)00021-6.
22. Star SL, Griesemer JR. Institutional ecology, "translations" and boundary objects: Amateurs and professionals in Berkeley's Museum of Vertebrate Zoology, 1907-1939. Soc Stud Sci. 1989;19(3):387-420. https://doi.org/10.1177/030631289019003 001.

23. Fujimura J. Crafting science: standardized packages, boundary objects, and "Translation." In: Pickering A editor. Science as practice and culture. University of Chicago Press; 1992. p. 168-211.

24. Håland E, Røsstad T, Osmundsen TC. Care pathways as boundary objects between primary and secondary care: experiences from Norwegian home care services. Health. 2015;19(6):635-51. https://doi.org/10.1177/1363459314567789.

25. Carlile PR. A pragmatic view of knowledge and boundaries: boundary objects in new product development. Organ Sci. 2002;13(4):442-55. https://doi.org/10.1287/orsc.13.4.442.2953.

26. Sapsed J, Salter A. Postcards from the edge: local communities, global programs and boundary objects. Organ Stud. 2004;25(9):1515-34. https://doi.org/10.1177/0170840604047998.

27. Bronkhorst LH, Akkerman SF. At the boundary of school: continuity and discontinuity in learning across contexts. Educ Res Rev. 2016;19:18-35. https://doi.org/10.1016/j.edurev.2016.04.001.

28. Trompette P, Vinck D. Revisiting the notion of boundary object. Revue d'anthropologie des connaissances. 2009;3(1):3-25. https://doi.org/10.3917/rac.006.0003.

29. Star SL. This is not a boundary object: reflections on the origin of a concept. Sci Technol Human Values. 2010;35(5):601-17.

30. Wenger E. Communities of practice: learning, meaning and identity. Cambridge: Cambridge University Press; 1998.

31. Kimble C, Grenier C, Goglio-Primard K. Innovation and knowledge sharing across professional boundaries: political interplay between boundary objects and brokers. Int J Inf Manag. 2010. https://doi.org/10.1016/j.ijinfomgt.2010.02.002.

32. Carlile P. Transferring, translating, and transforming: an integrative framework for managing knowledge across boundaries. Organ Sci. 2004;15:555-68. https://doi.org/10.1287/orsc.1040.0094.

33. Bishop S, Waring J. From boundary object to boundary subject; the role of the patient in coordination across complex systems of care during hospital discharge. Soc Sci Med. 2019. https://doi.org/ 10.1016/j.socscimed.2019.112370.

34. Fox NJ. Boundary objects, social meanings and the success of new technologies. Sociology. 2011;45(1):70-85. https://doi.org/ $10.1177 / 0038038510387196$.

35. Hsieh HF, Shannon SE. Three approaches to qualitative content analysis. Qual Health Res. 2005;15(9):1277-88. https://doi.org/ $10.1177 / 1049732305276687$.

36. Varpio L, Ajjawi R, Monrouxe LV, O'Brien BC, Rees CE. Shedding the cobra effect: problematising thematic emergence, triangulation, saturation and member checking. Med Educ. 2017;51(1):40-50. https://doi.org/10.1111/medu.13124.

37. Tong A, Sainsbury P, Craig J. Consolidated criteria for reporting qualitative research (COREQ): a 32-item checklist for interviews and focus groups. Int J Qual Health Care. 2007;19(6):349-57. https://doi.org/10.1093/intqhe/mzm042.

38. Bailo L, Guiddi P, Vergani L, Marton G, Pravettoni G. The patient perspective: investigating patient empowerment enablers and barriers within the oncological care process. Ecancermedicalscience. 2019;13:912. https://doi.org/10.3332/ecancer.2019.912.

39. Prip A, Moller KA, Nielsen DL, Jarden M, Olsen MH, Danielsen AK. The patient-healthcare professional relationship and communication in the oncology outpatient setting: a systematic review. Cancer Nurs. 2018;41(5):E11-22. https://doi.org/10.1097/NCC. 0000000000000533.

40. McCaffrey SA, Chiauzzi E, Chan C, Hoole M. Understanding 'Good Health care' from the patient's perspective: development of a conceptual model using group concept mapping. Patient. 2019;12(1):83-95. https://doi.org/10.1007/s40271-018-0320-x. 
41. Weiner SJ, Schwartz A, Sharma G, Binns-Calvey A, Ashley N, Kelly B, et al. Patient-centered decision making and health care outcomes an observational study. Ann Intern Med. 2013;158(8):573. https://doi.org/10.7326/0003-4819-158-8-20130 4160-00001.

42. Busch IM, Moretti F, Travaini G, Wu AW, Rimondini M. Humanization of care: key elements identified by patients, caregivers, and healthcare providers. A systematic review. Patient. 2019;12(5):461-74. https://doi.org/10.1007/s40271-019-00370-1.

43. Berger R, Bulmash B, Drori N, Ben-Assuli O, Herstein R. The patient-physician relationship: an account of the physician's perspective. Israel J Health Policy Res. 2020;9(1):33. https://doi.org/ 10.1186/s13584-020-00375-4.

44. Garman AN, Johnson TJ, Lynch EB, Satjapot S. Care provider perspectives on medical travel: a three-country study of destination hospitals. Health Mark Q. 2016;33(1):48-58. https://doi.org/ 10.1080/07359683.2016.1131579.

45. Scott JG, Cohen D, Dicicco-Bloom B, Miller WL, Stange KC, Crabtree BF. Understanding healing relationships in primary care. Ann Fam Med. 2008;6(4):315-22. https://doi.org/10.1370/afm. 860.

46. Dudzinski DM, Alvarez C. Repairing, "Difficult" patient-clinician relationships. AMA J Ethics. 2017;19(4):364-8. https://doi.org/ 10.1001/journalofethics.2017.19.4.medu3-1704.

47. Gleason KT, Han H-R. Patient feedback on research studies: how to interpret feedback from the 'Aware' patient? Patient. 2021;14(1):147-8. https://doi.org/10.1007/s40271-020-00469-w.

48. Reid A-M, Ledger A, Kilminster S, Fuller R. Can the tools of activity theory help us in advancing understanding and organisational change in undergraduate medical education? Adv Health Sci Educ Theory Pract. 2014. https://doi.org/10.1007/ s10459-014-9553-1.

49. Ellaway R. Virtual patients as activities: exploring the research implications of an activity theoretical stance. Perspect Med Educ. 2014. https://doi.org/10.1007/s40037-014-0134-z.

50. Shields GE, Brown L, Wells A, Capobianco L, Vass C. Utilising patient and public involvement in stated preference research in health: learning from the existing literature and a case study. Patient. 2020. https://doi.org/10.1007/s40271-020-00439-2.

51. Thompson AG. The meaning of patient involvement and participation in health care consultations: a taxonomy. Soc Sci Med. 2007;64(6):1297-310. https://doi.org/10.1016/j.socscimed.2006. 11.002.

52. Vahdat S, Hamzehgardeshi L, Hessam S, Hamzehgardeshi Z. Patient involvement in health care decision making: a review. Iran Red Crescent Med J. 2014;16(1): e12454. https://doi.org/10.5812/ ircmj. 12454

53. Aujoulat I, d'Hoore W, Deccache A. Patient empowerment in theory and practice: polysemy or cacophony? Patient Educ Couns. 2007;66(1):13-20. https://doi.org/10.1016/j.pec.2006.09.008.

54. Wakefield D, Bayly J, Selman LE, Firth AM, Higginson IJ, Murtagh FE. Patient empowerment, what does it mean for adults in the advanced stages of a life-limiting illness: a systematic review using critical interpretive synthesis. Palliat Med. 2018;32(8):1288-304. https://doi.org/10.1177/0269216318 783919.

55. Bate P, Robert G. Experience-based design: from redesigning the system around the patient to co-designing services with the patient. Qual Saf Health Care. 2006;15(5):307-10. https://doi.org/ 10.1136/qshc.2005.016527.

56. Giardina TD, Haskell H, Menon S, Hallisy J, Southwick FS, Sarkar U, et al. Learning from patients' experiences related to diagnostic errors is essential for progress in patient safety. Health Affair. 2018;37(11):1821-7. https://doi.org/10.1377/hlthaff.2018. 0698.

57. Pitts PJ. Our most powerful weapon to fight COVID-19: patient involvement. Patient. 2020;13(3):255. https://doi.org/10.1007/ s40271-020-00421-y.

58. Pitts PJ. Towards meaningful engagement for the patient voice. Patient. 2019;12(4):361-3. https://doi.org/10.1007/ s40271-019-00366-x. 